\title{
Resenha: O Oximoro da Diversidade como Emblema da Contemporaneidade
}

ORTIZ, Renato. Universalismo e Diversidade. São Paulo: Boitempo, 2015.

Pedro Martins de Menezes. ${ }^{1}$

Resumo: Depois de um período universal ocupado das ideias de unidade, homogeneidade, pureza e absolutismo e de um período particular enredado nas noções de multiplicidade, heterogeneidade, hibridismo e relativismo, o mundo vê surgir um terceiro regime cultural: o período da diversidade, emblema do atual estágio da modernidade-mundo. Em seu novo livro, Renato Ortiz se debruça sobre esse debate buscando entender que posição a diversidade ocupa em relação às duas agendas que a antecederam, ou seja: estaria a diversidade mais próxima dos valores universais de unidade, homogeneidade, pureza e absolutismo ou dos conceitos particulares de multiplicidade, heterogeneidade, hibridismo e relativismo? Depois de atravessar um instigante percurso analítico, o autor chega à conclusão de que a diversidade é um oximoro, ou seja, um termo capaz de conciliar vetores opostos. Nesse sentido, o oximoro da diversidade enlaçaria as duas tendências precedentes, ainda que elas sejam antípodas, ensejando no presente uma espécie de universalidade particular capaz de criar uma multiplicidade única, uma heterogeneidade homogênea, um hibridismo puro e um relativismo absoluto. O objetivo dessa resenha é recuperar o argumento de Renato Ortiz para entender de que maneira o oximoro da diversidade funciona como um emblema da contemporaneidade.

Palavras-chave: Diversidade; Universal; Particular; Emblema; Oximoro.

\footnotetext{
${ }^{1}$ Bacharel e mestre em sociologia pela Universidade de Brasília (PPGSOL/UnB)
}

Latitude, Vol. 9, no 2, pp. 441-455, 2015

DOI: https://doi.org/10.28998/2179-5428.20150208 


\section{Introdução}

Um emblema é uma imagem que sintetiza um conjunto de processos. Ao operar de maneira metonímica, o emblema funciona como um símbolo que condensa uma problemática difusa, deixando assim evidente um quadro complexo na medida em que o traduz para uma representação gráfica mais simples. Semelhante à figuração de Norbert Elias (1994) - entendida por esse autor como a forma objetivada de um cruzamento de valências - o emblema é a marca tridimensional que aparece no ponto de inflexão em que várias linhas se interpelam.

Em seu último livro, intitulado "Universalismo e Diversidade" (2015), Renato Ortiz toma emprestado de Octavio Ianni (1986) essa ideia de emblema para analisar a questão da diversidade. Ao entendê-la como o emblema de nossos dias, Ortiz trata a diversidade como uma espécie de ícone da contemporaneidade, ou seja, como um feixe composto por várias forças do presente. Aos poucos, vai surgindo uma figura na encruzilhada analítica onde essas tendências se cortam e, para o autor, essa imagemsíntese, que ilumina a intersecção dessas reticularidades ao mesmo tempo em que é formada por elas, é a diversidade. Sendo assim, por cumprir o papel de emblema desse período, a diversidade emerge aos olhos do sociólogo como a coagulação dos fluxos que constituem o atual estágio da modernidade-mundo. Nesse caso, se queremos entender nosso tempo, é para a diversidade que devemos nos voltar; e é isso o que Renato Ortiz faz com maestria ao longo dos seis artigos que compõem a coletânea "Universalismo e Diversidade".

Além das dificuldades inerentes à escrita de qualquer livro, o autor de uma compilação de textos enfrenta obstáculos específicos, sendo o maior deles a necessidade de equilibrar os artigos que compõem a obra na linha tênue entre independência e dependência recíproca. Quer dizer: se por um lado cada capítulo deve apresentar uma faceta inédita do debate, por outro é preciso encontrar um fio condutor que atravesse os textos, para que assim possam se complementar e dialogar entre si, fazendo com que o leitor identifique ali partes de um mesmo todo. Pode-se afirmar sem medo que Ortiz cumpre o desafio, trazendo-nos uma obra que avança e sempre retorna para o mesmo ponto, ou seja, que se desdobra sem perder sua organicidade. Os artigos acham essa sintonia fina entre ineditismo e coesão 
porque funcionam como entradas diferentes para um mesmo problema. Apresentando a estrutura prismática de um topázio, "Universalismo e Diversidade" tem variedade e espinha dorsal, já que nos mostra diferentes faces de um só objeto. Para alcançar essa desejada liberdade condicional, o autor disseca o conceito de diversidade, operando resgates sócio-genéticos que nos ajudam a compreender que forças se cortam para formar esse emblema do nosso tempo. Vejamos então que vetores são esses.

\section{O Universal e o Particular}

Sem dúvidas, a diversidade é a grande agenda cultural do presente. Embora o termo seja velho, depois de ter sido tematizada em dois importantes documentos recentemente lançados pela UNESCO - a Declaração Universal Sobre a Diversidade Cultural (2002) e a Convenção Sobre a Proteção e Promoção da Diversidade das Expressões Culturais (2005) - a ideia de diversidade foi ressignificada e ganhou novo fôlego, despontando como a palavra-chave capaz de organizar o debate e as políticas públicas em matéria de cultura no atual estágio da modernidademundo. Para mostrar essa nova silhueta da diversidade, que a coroou como emblema cultural contemporâneo, o livro de Ortiz recua no tempo, mapeando tendências antigas que se cruzam nos dias de hoje para elevar a diversidade a esse nível. Nesse emaranhado de valências, duas linhas parecem mais nítidas: o universal e o particular.

Antes de se materializar no emblema da diversidade que adotou hoje, o debate cultural atravessou dois períodos: um período universal e um período particular. Durante a fase universal, vemos um interesse pelas ideias de unidade, homogeneidade, pureza e absolutismo; enquanto que na época particular, a atenção se volta para as noções de multiplicidade, heterogeneidade, hibridismo e relativismo. Quer dizer, se no período universal a ênfase era o monismo e a perenidade, no período particular uma preocupação com o idiossincrático, o contingente e o étnico inaugura uma fase mais polissêmica da história. Entendamos essas duas épocas.

O período universal se desenrolou durante o século XIX, tempo que corresponde ao auge da empresa colonial do Ocidente, quando a Europa ocupou os demais continentes, drenando seus recursos e submetendo seus nativos a um regime de completa dependência. Como Ortiz aponta, o projeto modernizador em curso no século XIX promoveu a autonomização de várias esferas da sociedade, fazendo assim com que o indistinto tecido do social se fragmentasse em uma porção de diferentes campos 
relativamente independentes. Aos poucos, a sociedade ia deixando de ser uma pátina contínua para se ver dividida em áreas cujas fronteiras pareciam cada vez mais sólidas, tais como economia, arte, ciência, etc. No entanto, embora fosse tido como um índice de modernização, acreditava-se que esse processo de diferenciação dos campos sociais ameaçava a coesão da sociedade, na medida em que trazia consigo o risco de sua completa desintegração. Quer dizer, ainda que fosse necessário separar os campos, não se podia deixar que esses projeto fosse longe demais, pois se os campos se distanciassem muito uns dos outros, o monolito da sociedade se dissolveria em uma profusão de ilhas à deriva. Para os teóricos da época, o perigo dessa diluição do todo em partes isoladas representava a crise moral que anos mais tarde Durkheim chamaria de anomia (2004).

Nesse sentindo, para que a sociedade se diferenciasse internamente sem mergulhar na total pulverização, o estímulo à autonomização dos campos deveria ser compensado pela busca de um discurso que perpassasse todas essas esferas semi-independentes, para que assim o arranjo ganhasse organicidade. Mas que discurso poderia desempenhar esse papel de eixo? Para responder essa pergunta é necessário atentar para uma dinâmica em curso na época: a transferência de prestígio da religião para a ciência. Como se sabe, o século XIX foi um período de grandes avanços científicos, tanto de um ponto de vista técnico (invenções, melhoramentos, etc.), quanto teórico (novas concepções sobre o homem e a natureza, como a teoria da evolução das espécies de Darwin (2013), apresentada em 1859). Aos poucos, o homem foi deixado de se ver como um filho de Deus para se descobrir uma entidade biológica complexa. Com isso, as respostas para os enigmas da vida deixaram de repousar no passado obscuro apresentado pela igreja e passaram a ser buscadas no futuro que o evolucionismo científico descortinava. A rosa dos ventos do conhecimento mudava de direção: não importa mais quem éramos e de onde viemos, mas quem seremos e para onde vamos. Com a inversão desse vetor, a razão ganha prestígio em detrimento da fé, pois só a ciência, e não a igreja, seria capaz de dar uma resposta satisfatória para as novas interrogações que surgiam. Diante disso, percebeu-se que aquele discurso capaz de costurar os campos e impedir a dissolução da sociedade não poderia vir dos padres, mas dos cientistas. Foi o que aconteceu. Inspirada pelo racionalismo e pelo acento futurista da teoria da evolução, a ciência elaborou o único discurso capaz de ligar os campos sociais, permitindo 
assim que se diferenciassem sem que a vida se fraturasse: $o$ discurso do progresso. A partir daí, a ideia de progresso desponta no século XIX como a grande teoria do seu tempo, a única resposta possível para os problemas que a sociedade da época enfrentava.

Como Ortiz demonstra, para o discurso do progresso, a história é uma linha reta que aponta sempre para a mesma direção. Ou seja: tem-se aqui uma concepção de história única, linear e teleológica. De acordo com essa visão, portanto, os povos não podem ser donos de suas respectivas histórias, pois estariam todos arrastados pela mesma correnteza. Sendo assim, para essa perspectiva, as diferenças culturais entre os povos não se deviam ao fato de que cada um deles possuía suas particularidades locais, mas sim porque tais grupos se encontrariam estacionados em diferentes estágios cronológicos de uma mesma hierarquia evolutiva. As diferentes culturas não eram vistas de maneira sincrônica, como respostas específicas para perguntas específicas, mas como etapas de uma mesma história única, linear e teleológica. Como já se pode imaginar, o topo dessa hierarquia era ocupado pelo Europa, entronizada como cultura mais desenvolvida do mundo. Enquanto isso, à luz dessa ideia, as outras culturas eram diferentes da Europa não porque estavam ocupadas de seus respectivos projetos, mas porque se encontrariam fossilizadas em um período histórico pelo qual o Velho Mundo já teria passado há muito tempo.

Coroada pelo discurso do progresso como fim da história, a cultura europeia se firma como modelo a ser seguido pelas demais. Em paralelo a isso, as outras culturas do mundo são encaradas como contingências, "europas" que deram errado. A conclusão desse pensamento é que o Ocidente, içado a categoria de pauta normativa eterna, tem o direito de interferir nos demais povos, que não passam de comunidades incompletas, estagnadas nos degraus iniciais do progresso. De acordo com esse pensamento, a interferência da Europa no resto do mundo não seria boa só para ela, mas principalmente para o resto do mundo, que supostamente precisaria da ingerência de uma cultura avançada para seguir no rumo do progresso até que seu projeto civilizatório estivesse concluído. Desse jeito, o expansionismo colonial europeu ganha ares de filantropia, e a cultura do Ocidente se eleva à condição universal: única, homogênea, pura e absoluta.

Como o futuro se encarregaria de provar, esse pensamento levou o mundo para bem longe dos ideais de boa sociedade que o discurso do progresso prometia. Depois de um século XIX sangrento, a humanidade 
entrou em uma guerra mundial que por consequência trouxe uma segunda ainda mais monstruosa. Com o fracasso desse programa, viu-se que era preciso erguer uma sociedade sobre novas bases, e foi investido dessa missão de apontar a bússola do desenvolvimento para uma direção mais pacífica e humanitária que em 1945 um conjunto de países resolveu criar a Organização das Nações Unidas (ONU) e dentro dela a Organização das Nações Unidas para Educação, Ciência e Cultura (UNESCO). De fato, há de se reconhecer que arbitrariedades irrefletidamente aceitas antes de 1945 foram varridas da geopolítica internacional depois que os órgãos foram criados, no entanto, é curioso observar que uma ideia que alicerçou a barbárie da colonização e das duas guerras mundiais, mais do que abraçada, foi reafirmada pela ONU e pela UNESCO: a ideia de universal. Olhando a carta de fundação dessas duas entidades (ONU, 1945; UNESCO, 1945), e a "Declaração Universal dos Direitos Humanos", lançada por elas em 1948, vemos que ali o universal é amplamente defendido. Pode-se dizer que agora adota-se um outro universal, mas a categoria "universal" propriamente dita permanece. Ou seja, muda-se o conteúdo, mas se mantém a forma: antes o universal se baseava na violência, na assimetria de poder e no evolucionismo; depois de 1945, o conceito se enraizou na paz, na igualdade e na bondade. Entretanto, seja a serviço da destruição ou da concórdia, o universal sempre foi o lastro da agenda política de cada época. Mas esse cenário estava prestes a mudar.

Para Ortiz, o universal começa a perder centralidade com a derrocada do discurso do progresso, que lhe servia de amparo. O autor explica essa queda da seguinte maneira: com já foi dito, a noção de progresso postulava uma história única, linear e teleológica, criando assim um só gabarito que hierarquizava culturas coexistentes em diferentes estágios de desenvolvimento. De acordo com essa visão, a diferença entre as culturas não se explicava por idiossincrasias contextuais, mas porque cada uma delas se encontrava amarrada a um diferente patamar evolutivo, estando a Europa no degrau mais elevado desse processo. Assim, ao propor uma história única, linear e teleológica, o discurso do progresso enfileirava os povos em uma reta crescente de desenvolvimento, onde cada cultura representava um tempo histórico diferente, partindo do mais atrasado ao mais evoluído. Entretanto, depois de afundar o mundo na carnificina da colonização e das guerras, o discurso do progresso caiu em descrédito, e o modelo histórico monista que postulava foi substituído pela 
ideia de que muitos processos históricos (co)existiam, pois cada povo elaborava seu próprio caminho baseado em suas especificidades culturais. Agora que a seta do progresso vira um emaranhado de processos locais contemporâneos, a justificativa para a diferença entre os povos não é mais buscada na suposição de que as culturas encarnariam tempos diferentes de uma mesma história, mas histórias diferentes de um mesmo tempo. A variedade se baseia no fato de que as culturas se espalham por locais diferentes do planeta, e não por eras diferentes da história. Ao invés de várias épocas em um mesmo lugar, o que se tem então são vários lugares em uma mesma época. Antes, o mundo era a história e cada pedaço seu, um período; agora o mundo é uma geografia, e cada pedaço seu, um local. Como Ortiz bem resume, o colapso do discurso do progresso promove uma espacialização do tempo, movimento esse que converte uma verticalidade histórica em uma horizontalidade geográfica.

Nesse sentido, podemos dizer então que durante a vigência do discurso do progresso só havia uma única cultura no mundo, mas os povos eram diferentes porque estariam petrificados em diferentes estágios evolutivos dessa cultura. Devido a esse monismo cultural, era plausível buscar um universal. Entretanto, com o crepúsculo do discurso do progresso, a rocha da cultura se dilui em uma profusão de culturas diferentes. Passa-se da era de uma cultura com vários tempos para a fase de um tempo com várias culturas. Ao invés da flecha do progresso, com um só passado e um só futuro, emerge um novelo de histórias de vários locais, cada uma com sua respectiva tradição e sua respectiva modernidade. Diante dessa polissemia iniciada com a falência do progresso, o universal perde a capacidade de organizar o debate cultural, e em seu lugar surge um interesse pelo mapeamento dessas especificidades, dessas contingências, dessas experiências contextuais; dito de maneira direta, surge a busca pelo particular.

Passando em revista o que foi dito, de acordo com Ortiz, o esgotamento do discurso do progresso promove uma espacialização do tempo, o que transforma o monolito da cultura em um arquipélago polissêmico, fazendo assim com que o interesse por um universal único, homogêneo, puro e absoluto dê lugar à busca por particularidades múltiplas, heterogêneas, híbridas e relativas. ${ }^{2}$

2 Segundo o autor, a própria sociologia desempenha um papel relevante nesse deslocamento, plantando a semente dessa mentalidade, pois é com a teoria de Durkheim 
Depois de um período universal ocupado do único, do homogêneo, do puro e do absoluto e de um período particular enredado no múltiplo, no heterogêneo, no híbrido e no relativo, chegamos ao presente, época em que emerge um terceiro regime: a diversidade, emblema da cultura no mudo contemporâneo. Diante disso, resta saber como se posiciona a diversidade em relação aos dois períodos antagônicos que a antecederam: estaria a diversidade mais próxima de um universal único, homogêneo, puro e absoluto ou de um particular múltiplo, heterogêneo, híbrido e relativo?

A meu ver, a resposta que Ortiz dá a essa pergunta é a grande contribuição - tanto empírica, quanto teórico-metodológica - que seu livro traz para o debate. Vejamos então que conclusão é essa.

\section{A Diversidade entre o Universal e o Particular}

O emblema da diversidade é uma terceira onda que surge depois de duas experiências contrárias: a busca por um universal único, homogêneo, puro e absoluto e o rastreamento de particulares múltiplos, heterogêneos, híbridos e relativos. Por suceder esses dois programas antitéticos, é de se esperar que o terceiro período da diversidade tenha que escolher entre um ou outro. Quer dizer, ou a diversidade se filia a um universal único, homogêneo, puro e absoluto ou a um particular múltiplo, heterogêneo, híbrido e relativo, afinal, essas duas narrativas são opostas, e narrativas opostas são, por definição, imiscíveis, certo? Errado.

Em seu livro, Ortiz nos mostra que há uma noção capaz de conciliar termos contrários: a noção de oximoro. Nas palavras do autor um oximoro é aquela ideia que

"Combina termos de sentidos contraditórios, mas que, em determinada situação, reforçam sua expressão. (...) Como figura de linguagem, ela exprime a coerência de algo que parece ser mutuamente excludente. (ORTIZ, 2015, p. 35)

Na dinâmica do oximoro, ideias rivais se fortalecem, e não se fortalecem apesar de rivalizarem, mas justamente porque rivalizam, pois, para os fins desse conceito, oposições também podem ser construtivas. Assim como a

(2003) que as categorias do conhecimento passam a ser vistas como construções sociais que variam de uma cultura para outra, e não mais como um a priori trans-histórico interno à razão, como defendia Kant (2012). À medida que esse acento relativista foi se desenvolvendo, foram surgindo defesas mais radicais da ideia de particularidade, como por exemplo o pensamento pós-moderno, cujo membro mais representativo é Lyotard, que acreditava em uma irreconciliável fragmentação da cultura (2010). 
ciranda dos planetas no universo é harmonicamente mantida pela mútua anulação de forças gravitacionais contrárias, a simetria do oximoro é assegurada pela repelência que, por ser mutuamente exercida, se conforma enquanto união. O modelo precisa estar rigorosamente desenhado para que as duas partes gravitem uma ao redor da outra, unindo-se e se afastando com a mesma força, que assim se invalida. Se o envolvimento superar a negação, os conceitos colidem; se o contrário ocorrer, o arranjo se dissolve. Sendo assim, o que se observa no fenômeno do oximoro não é nem uma fusão nem uma exclusão de ideias - ou são ambas com a mesma intensidade -, mas um tenso equilíbrio entre esses dois momentos. O modelo converge na sua divergência espelhada, equilibrando-se na própria tensão ao conseguir a proeza de repousar em seu conflito. Para que uma constelação de sentidos sobreviva, não se pode aproximar os elementos favoráveis e expulsar aqueles aparentemente perigosos. Muitas vezes, o que garante a continuidade do arranjo é o simétrico alinhamento das forças atrativas e repelentes, o que faz com que os vetores se anulem ao se envolverem e alienarem com a mesma intensidade. À maneira da cismogênese de Gregory Bateson (2008) - conceito que permite que os princípios opostos de permanência e mudança se fortaleçam mutuamente - no oximoro, ideias antípodas criam vínculos que se fundam em sua recíproca negação. Através dessa ideia, o que parece contraditório se revela complementar, e aquilo que soa ambíguo se demonstra ambivalente. É isso o que o oximoro é: uma ambivalência que harmoniza forças inimigas. O hiato que as separa é o espaço que compartilham. O corte que as divide é o elo que as conecta.

Voltemos à nossa dúvida: que posição a diversidade ocupa em relação aos dois programas antitéticos que a precederam? Estaria a diversidade interessada em um universal único, homogêneo, puro e absoluto ou em um particular múltiplo, heterogêneo, híbrido, e relativo? Acreditava-se que a diversidade precisaria escolher entre um dos dois projetos porque, como se tratam de agendas opostas, essas metas só poderiam ser inconciliáveis. Mas, se pensarmos a diversidade como um oximoro, vemos que é desnecessário escolher entre um dos polos desse antagonismo, já que podemos ter ambos, uma vez que o oximoro é um mecanismo capaz de enlaçar contrários. É exatamente isso que Ortiz faz: para o autor, a diversidade opera um oximoro entre universal e particular. Portanto, o conceito de diversidade nem abraça exclusivamente as ideias 
universais de unidade, homogeneidade, pureza e absolutismo, nem se enraíza apenas nas noções particulares de multiplicidade, heterogeneidade, hibridismo e relativismo. Ao invés disso, o oximoro da diversidade aproxima esses oposto em uma espécie de universalidade particular, promovendo assim uma multiplicidade única, uma heterogeneidade homogênea, um hibridismo puro e um relativismo absoluto. De um ponto de vista empírico, isso quer dizer que, por um lado, a diversidade cultiva a polissemia, mas por outro lado, se esforça para que essa variedade se conforme dentro de um mesmo perímetro. Buscam-se as muitas especificidades para que todas elas se agrupem em um mesmo paradigma de sólidas arestas. Ocorre com a diversidade aquilo que Erlmann chama de "Síndrome de Benetton"3, ou seja: somos todos diferentes e esse é nossa característica comum. Toda espécie tem um traço exclusivo que a faz ser uma espécie, ou seja, uma característica que se marca em todos os membros do grupo e se omite dos membros de outros grupos, de modo que aquela comunidade seja distinta de tudo o que está fora dela porque tudo é indistinto dentro dela. Na espécie humana, esse traço exclusivo é a própria diferença: a marca que temos e que nenhuma outra espécie tem é o fato de sermos um grupo cujos membros são diferentes uns dos outros, e é isso o que nos aproxima. O que faz do grupo humano um grupo, igual a si mesmo e diferente de tudo o mais, é essa característica comum a todos os homens: a ausência de uma característica comum a todos os homens. Já que a diferença é a qualidade que partilhamos, a particularidade é nosso traço universal e a universalidade é nosso traço particular. As muitas e diferentes idiossincrasias atestam a riqueza desse liso monolito que é a família humana. Somos uma espécie singular porque somos a única espécie plural. Ao que tudo indica, para o oximoro da diversidade, mais vale a máxima que Deleuze e Guattari cunharam em "Mil Platôs": "Há exatamente uma história universal, mas é a da contingência" (2011, p. 10).

Um exemplo nos ajuda a ver essa dinâmica: os documentos em defesa da diversidade lançados pela UNESCO no início deste século, já citados no começo do texto $(2002,2005)$, se baseiam nas resoluções eivadas de universalismo da carta de fundação do órgão e na Declaração Universal dos Direitos humanos, redigidas na década de 1940. Isso quer dizer que,

3 "Homogeneidade e diversidade são dois sintomas do que se pode chamar de Síndrome de Benetton: quanto mais pessoas ao redor do mundo usam o mesmo traje, mais o comercial celebra a diferença." (ERLMANN, 1996, p. 469). 
nos dias de hoje, a diversidade é tomada como um valor universal. "A valorização das diferenças se faz em nome de um ideal também universalista." (ORTIZ 2015, p. 35). Para a gramática do oximoro, a diversidade atesta a especificidade do gênero humano. Defende-se uma variedade cultural de povos, mas ela é afirmada como uma universalidade natural de uma mesma humanidade. Como Ortiz resume: "O diverso tornase um bem comum" (Ibid.)

"Dizer que as culturas são um 'patrimônio da humanidade' significa considerar a diversidade um traço partilhado por todos, que deveríamos cultivar e respeitar." (Ibid. p. 34)

Em um de seus trabalhos mais recentes, Néstor García Canclini afirma:

"Quando falo em sociedade sem relato (...) refiro-me à condição histórica na qual nenhum relato organiza a diversidade em um mundo cuja interdependência leva muitos a sentirem falta dessa estruturação". (CANCLINI, 2012, pp. 25, 26).

Mas o que o antropólogo não percebe é que é o próprio relato da diversidade que organiza a polissemia do mundo. Quando diz que, no presente, não existem "teorias gerais que abarquem sua atual diversidade" (Ibid. p. 238), Canclini não repara que é justamente a diversidade a tal teoria geral que abarca a profusão de relatos menores que insistem em se multiplicar. Felizmente, Ortiz não incorre no mesmo erro, pois, ao definir a diversidade como um oximoro, entende que o conceito promove tanto o particular quanto o universal: por um lado, a diversidade estimula a proliferação de diversos relatos diferentes, por outro, encerra-os dentro de uma mesma fronteira impermeável. Na diversidade, a diferença é celebrada e contida: promovo-se o particular, desde que inserido numa rígida moldura universal.

Iniciei o texto falando que um emblema é uma representação simples que ilustra um quadro de forças complexo. Pois bem, o emblema da diversidade é a tradução imagética da elaborada configuração tecida pelos vetores universal e particular. Essas forças são opostas, mas na placidez do emblema da diversidade se encontram. O que Ortiz nos mostra é que a própria rivalidade das forças promove a estabilidade do emblema. Essa imagem é uma sucessão de cortes, uma linha ininterrupta de rupturas. 
No presente, há uma continuidade externa mantida por descontinuidades internas: esse é o tempo da diversidade, uma imagem que concilia a luta entre o universal e o particular, por isso, como sinalizado no título, "o oximoro da diversidade é um emblema da contemporaneidade." (ORTIZ, 2015, p. 35). Em meio a tantas saídas fáceis e maniqueístas, o refinamento que essa conclusão de Renato Ortiz alcança faz com que seu novo livro seja exatamente como o objeto que estuda: emblemático.

\section{Referências}

BATESON, Gregory. Naven. São Paulo: Edusp, 2008.

CANCLINI, Néstor García. A Sociedade Sem Relato. São Paulo: Edusp, 2012.

DARWIN, Charles. A Origem das Espécies. São Paulo: Hemus, 2013.

DELEUZE, Gilles. \& GUATTARI, Felix. Mil Platôs. São Paulo: 34, 2011.

DURKHEIM, Émile. As Formas Elementares da Vida Religiosa. São Paulo: Martins Fontes, 2003.

. Da Divisão do Trabalho Social. São Paulo: Martins Fontes, 2004.

ELIAS, Norbert. A Sociedade dos Indivíduos. Rio de Janeiro: Zahar, 1994.

ERLMANN, V. The Aesthetics of Global Imagination: reflections on World Music in the 1990s. In: Public Culture 1996 - 8. 467-487. Chicago: University of Chicago, 1996.

IANNI, Octavio. Florestan Fernandes e a Formação da Sociologia Brasileira. In: . Florestan Fernandes. São Paulo: Ática, 1986.

KANT, Immanuel. Crítica da Razão Pura. Petrópolis: Vozes, 2012.

LYOTARD, J. Condição Pós-moderna. Rio de Janeiro: Jose Olympio, 2010.

ONU: Carta das Nações Unidas e Estatuto da Corte Internacional de Justiça. 1945.

ORTIZ, Renato. Universalismo e Diversidade. São Paulo: Boitempo, 2015.

UNESCO: Constituição da Organização das Nações Unidas para Educação, Ciência e Cultura, 1945 : Declaração Universal dos Direitos Humanos, 1948 : Declaração Universal Sobre Diversidade Cultural, 2002.

: Convenção Sobre a Proteção e Promoção das Diversidade das Expressões

Culturais, 2005. 